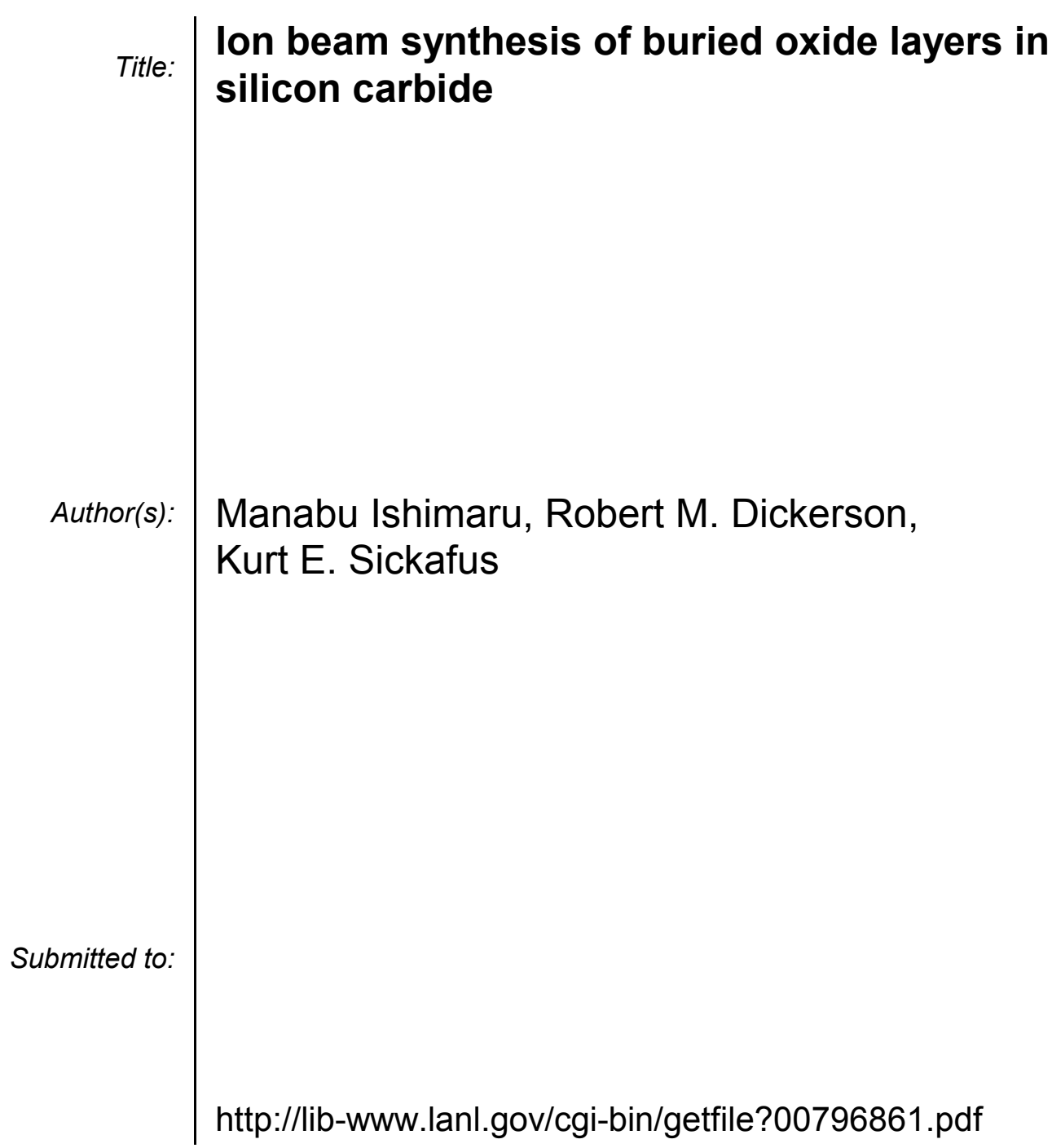

Los Alamos National Laboratory, an affirmative action/equal opportunity employer, is operated by the University of California for the U.S. Department of Energy under contract W-7405-ENG-36. By acceptance of this article, the publisher recognizes that the U.S. Government retains a nonexclusive, royaltyfree license to publish or reproduce the published form of this contribution, or to allow others to do so, for U.S. Government purposes. Los Alamos National Laboratory requests that the publisher identify this article as work performed under the auspices of the U.S. Department of Energy. Los Alamos National Laboratory strongly supports academic freedom and a researcher's right to publish; as an institution, however, the Laboratory does not endorse the viewpoint of a publication or guarantee its technical correctness. 


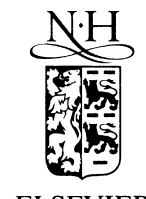

Nuclear Instruments and Methods in Physics Research B 166-167 (2000) 390-394

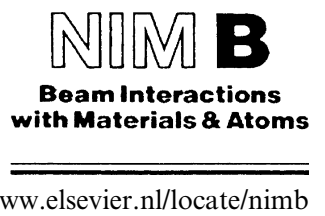

\title{
Ion beam synthesis of buried oxide layers in silicon carbide
}

\author{
Manabu Ishimaru ${ }^{\mathrm{a}, \mathrm{b}, *}$, Robert M. Dickerson ${ }^{\mathrm{a}}$, Kurt E. Sickafus ${ }^{\text {a }}$ \\ ${ }^{a}$ Materials Science and Technology Division, Los Alamos National Laboratory, Los Alamos, NM 87545, USA \\ ${ }^{\mathrm{b}}$ Department of Materials Science and Engineering, Kyushu University, Hakozaki, Fukuoka 812-8581, Japan
}

\begin{abstract}
A field emission gun scanning transmission electron microscope equipped with an energy-dispersive X-ray spectrometer (EDX) and an electron energy loss spectrometer (EELS) has been used to characterize the microstructures, elemental distributions, and chemical bonding states of oxygen ion implanted silicon carbide ( $\mathrm{SiC}$ ). $6 \mathrm{H}-\mathrm{SiC}$ substrates with the $\left(\begin{array}{lll}0 & 0 & 0\end{array}\right)$ orientation were implanted with $180 \mathrm{keV}$ oxygen ions at $650^{\circ} \mathrm{C}$ to fluences of $0.7 \times 10^{18}$ and $1.4 \times 10^{18}$ $\mathrm{cm}^{-2}$. A continuous amorphous layer is formed in the as-implanted state under these irradiation conditions. The amorphous layer is uniform in the low-dose sample, while it consists of three layers in the high-dose one. EDX maps of elemental distributions suggest that the layered structure in the latter sample originates from compositional fluctuations of silicon, carbon and oxygen. EELS measurements suggest that the amorphous regions in the high-dose sample consist of well-defined $\mathrm{SiO}_{2}$ layer which is accompanied by sp²-bonded carbon. ㄷ 2000 Published by Elsevier Science B.V. All rights reserved.
\end{abstract}

PACS: 61.16.Bg; 61.72.Ss; $81.40 . \mathrm{Wx}$

Keywords: SiC; Semiconductor-on-insulator (SOI); STEM; EDX; EELS; Elemental mapping

\section{Introduction}

Silicon carbide ( $\mathrm{SiC})$ is an important semiconductor for application in power and hightemperature electronics, ultraviolet sensor, and high-speed devices. These applications are based upon its wide energy band gap, high-electronsaturated drift velocity, high thermal conductivity, and other factors. These outstanding properties of

\footnotetext{
${ }^{*}$ Corresponding author. Tel.: +81-92-642-3677; fax: +81-92632-0434.

E-mail address: ishimaru@zaiko.kyushu-u.ac.jp (M. Ishimaru).
}

$\mathrm{SiC}$ are expected to extend the range of semiconductor applications. One recent trend in the semiconductor industry is to develop semiconductor-on-insulator (SOI) structures on which devices are dielectrically insulated from one another (for a review, see [1]). In addition, the formation of buried oxide layers in $\mathrm{SiC}$ can be used as a lower cladding layer for optical waveguides [25]. Therefore, it is technologically of great importance to develop SiC-on-insulator structures.

Some researchers performed oxygen ion implantation into $\mathrm{SiC}$ to synthesize a buried oxide layer, and analyzed the samples using Rutherford backscattering spectroscopy (RBS) [4,5], X-ray photoelectron spectroscopy (XPS) [4], and optical 
transmission and reflection measurements [5]. As a result, it has been suggested that the oxygen implantation into $\mathrm{SiC}$ is a possible way to develop $\mathrm{SiC}$-on-insulator structures. However, the results obtained by these measurement techniques are spatially averaged. As far as we know, no investigations have been conducted regarding microstructural analyses of oxygen implanted $\mathrm{SiC}$. Understanding the relationships between microstructure, elemental distributions, and chemical bonding states is important to clarify the formation mechanisms of buried oxide layers. In this study, we examined the microstructural features, chemical distribution and bonding in oxygen implanted SiC using a field emission gun scanning transmission electron microscope equipped with an energy-dispersive X-ray spectrometer (STEMEDX) and an electron energy loss spectrometer (STEM-EELS). This instrument has higher spatial resolution than is obtained using conventional RBS and XPS, and can observe microstructure, composition, and chemical bonding states at the same time.

\section{Sample preparations}

The n-type $6 \mathrm{H}-\mathrm{SiC}$ single crystal wafers used in this study were obtained from Cree Research and were oriented on the [0 0001$]$ axis. Samples were irradiated with a $180 \mathrm{keV} \mathrm{O}^{+}$ion beam from a 200 $\mathrm{kV}$ ion implanter in the Ion Beam Materials Laboratory at Los Alamos National Laboratory. The implantation fluences were $0.7 \times 10^{18}$ and $1.4 \times 10^{18} \mathrm{O}^{+} \mathrm{cm}^{-2}$ and the ion beam flux was maintained at a constant flux of $\sim 6 \times 10^{13} \mathrm{O}^{+}$ $\mathrm{cm}^{-2} \mathrm{~s}^{-1}$ during the implantations. The ion beam was incident at a $5^{\circ}$ angle with respect to the sample normal [ $\left[\begin{array}{llll}0 & 0 & 0 & 1\end{array}\right]$ with minimized channeling effects. For implantation, samples were held by clips onto a nickel block which was maintained at a constant temperature $\left(650^{\circ} \mathrm{C}\right)$ by an internal heater. No special care was taken to thermally contact the wafers to the block, so sample temperature during irradiation was higher than the block temperature as a result of beam heating.

A JEOL JEM-3000F transmission electron microscope (TEM) operated at $300 \mathrm{kV}$ was used to observe implantation-induced microstructures. Chemical information regarding elemental distributions and chemical bonding states was examined in a Vacuum Generator HB601 STEM electron microscope operated at $100 \mathrm{kV}$. Cross-sectional TEM and STEM samples were prepared by gluing an unirradiated $\mathrm{SiC}$ wafer to the surface of the irradiated SiC, cutting cross-sections of the samples (perpendicular to the irradiated surface), and using a tripod polishing technique to thin the specimens prior to ion milling with $4 \mathrm{keV} \mathrm{Ar}^{+}$ ions.

\section{Results and discussion}

Figs. 1(a) and (b) show bright-field TEM images of $6 \mathrm{H}-\mathrm{SiC}$ implanted with $180 \mathrm{keV}$ oxygen ions at $650^{\circ} \mathrm{C}$ to fluences of $0.7 \times 10^{18}$ and $1.4 \times 10^{18} \mathrm{~cm}^{-2}$, respectively. Three regions with
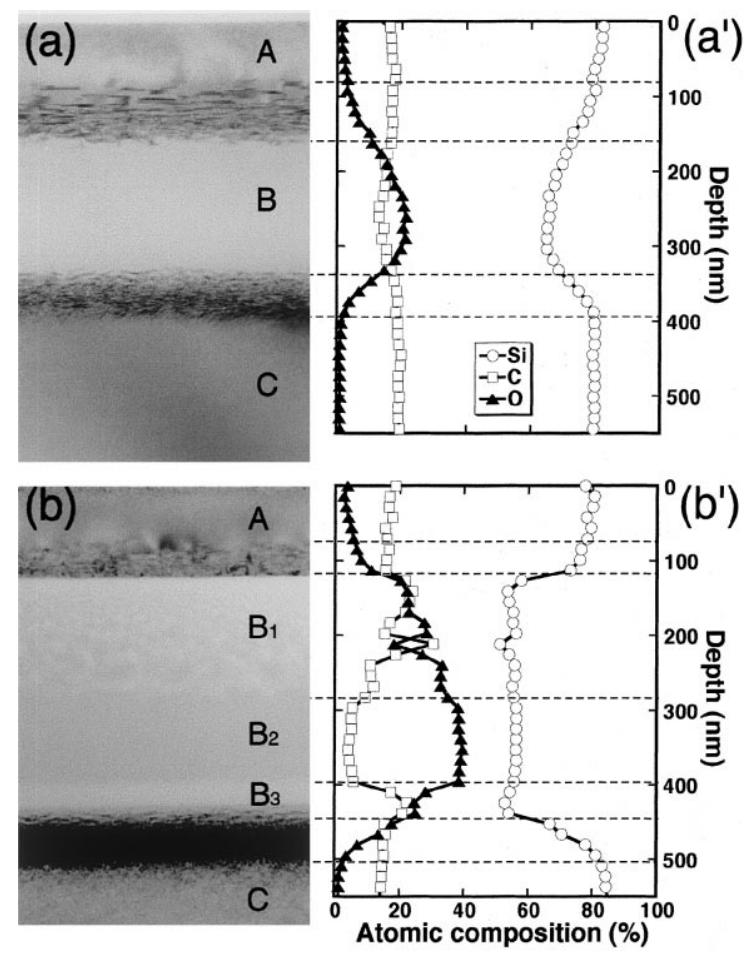

Fig. 1. Bright-field images and EDX compositional depth profiles of oxygen ion implanted $6 \mathrm{H}-\mathrm{SiC}$ to ion fluences of $\left(\mathrm{a}, \mathrm{a}^{\prime}\right) 0.7 \times 10^{18}$ and $\left(\mathrm{b}, \mathrm{b}^{\prime \prime}\right) 1.4 \times 10^{18} \mathrm{O}^{+} \mathrm{cm}^{-2}$. 
distinct image contrast are apparent in Figs. 1(a) and (b), as indicated by A, B and C. Selected-area diffraction observations revealed that regions $\mathrm{A}$ and $\mathrm{C}$ are single-crystalline $6 \mathrm{H}-\mathrm{SiC}$, while $\mathrm{B}$ is an amorphous phase. The top layer A (adjacent to the sample surface) contains minimal damage; this is a consequence of in situ defect annealing during the high-temperature implantation. High defect concentrations are observed in regions adjacent to the amorphous layer [6,7]. It should be noted that the amorphous layer (B) exhibits uniform image contrast in the lower-dose sample (Fig. 1(a)), while three distinct layers are visible in the higher-dose sample, as indicated by $B_{1}$ (bubbled or mottled contrast), $\mathrm{B}_{2}$ (dark contrast) and $\mathrm{B}_{3}$ (light contrast) (Fig. 1(b)).

Compositional depth profiles from the regions in Figs. 1(a) and (b) are illustrated in Fig. 1( $\left.\mathrm{a}^{\prime}\right)$ and $\left(b^{\prime}\right)$, respectively. For a material like $\mathrm{SiC}$ with oxygen, STEM-EDX results depend strongly on the sample thickness and geometry. This is because the soft X-ray fluorescence associated with carbon and oxygen $\left(\mathrm{C} \mathrm{K}_{\alpha}\right.$ at $282 \mathrm{eV}$ and $\mathrm{O} \mathrm{K}_{\alpha}$ at $\left.523 \mathrm{eV}\right)$ are easily absorbed within the sample or by other geometrical obstructions, so that carbon and oxygen concentrations may be severely underestimated. Therefore, the STEM-EDX data presented in Figs. $1\left(a^{\prime}\right)$ and $\left(b^{\prime}\right)$ are only intended to show qualitative trends. The upper layer (A) and substrate $(C)$ contain little oxygen; the oxygen signal first appears in the damaged regions within $\mathrm{A}$ and C. In the lower-dose sample (Fig. 1( $\left.\mathrm{a}^{\prime}\right)$ ), the oxygen concentration peaks near the center of the buried amorphous layer, and decreases toward the amorphous-to-crystalline interfaces. The elemental depth profiles are more complicated in the higherdose specimen (Fig. 1( $\left.b^{\prime}\right)$ ). The layer consisting of bubbled or mottled contrast $\left(\mathrm{B}_{1}\right)$ and the light contrast layer $\left(\mathrm{B}_{3}\right)$ are characterized by depleted silicon and oxygen concentrations and carbon accumulation is found in these regions.

To obtain detailed information regarding elemental distributions, two-dimensional elemental EDX maps from the $1.4 \times 10^{18} \mathrm{O}^{+} \mathrm{cm}^{-2}$ specimen are displayed in Fig. 2. Fig. 2(a) shows an annular dark-field image of the area analyzed in the maps in Figs. 2(b)-(d). Elemental maps were obtained by measuring the $\mathrm{K}_{\alpha}$ fluorescence intensity from
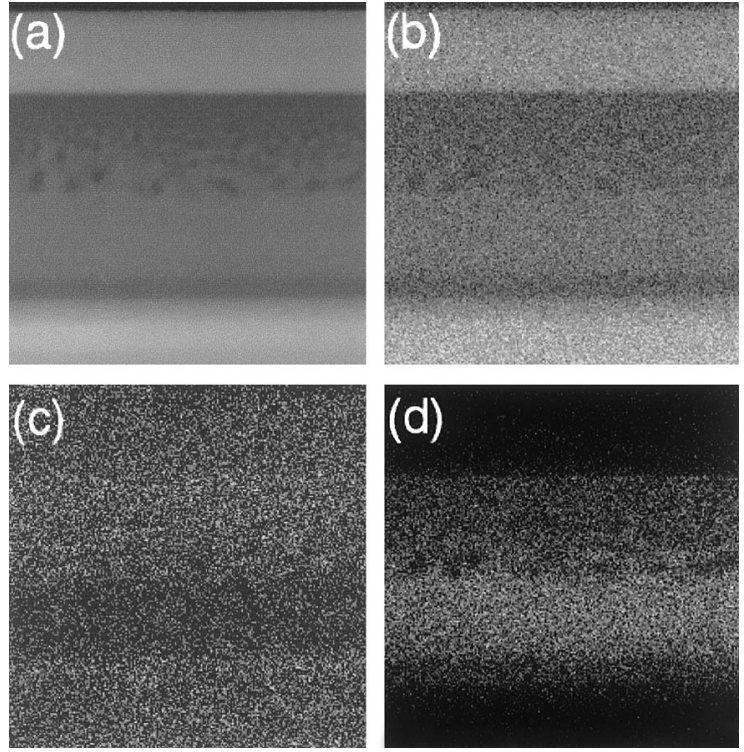

Fig. 2. Two-dimensional EDX elemental mapping of $1.4 \times 10^{18}$ $\mathrm{O}^{+} \mathrm{cm}^{-2}$ sample. (a) Annular dark-field image, and elemental mapping obtained from (b) Si, (c) $\mathrm{C}$ and (d) $\mathrm{O} \mathrm{K}_{\alpha}$ fluorescence peaks.

(b) silicon $(1740 \mathrm{eV})$, (c) carbon $(282 \mathrm{eV})$ and (d) oxygen $(523 \mathrm{eV})$. White contrast corresponds to high elemental concentration. It is clearly seen that the heterogeneous nature of the amorphous layer in Fig. 1(b) is due to compositional variations of silicon, carbon, and oxygen. By contrast, EDX maps confirmed that the lower-dose sample exhibits uniform elemental distributions within the amorphous layer (not shown). The trends in the elemental depth distributions shown in Fig. 2 are in good agreement with previous investigations using RBS [4,8] and XPS [4].

Fig. 3 illustrates (a) $\mathrm{Si}_{2,3}$ edge and (b) $\mathrm{C} \mathrm{K}$ edge EELS spectra obtained from different layers in $6 \mathrm{H}-\mathrm{SiC}$ implanted with $1.4 \times 10^{18} \mathrm{O}^{+} \mathrm{cm}^{-2}$. The incident electron beam was focused on $\mathrm{a} \sim 1 \mathrm{~nm}$ spot and the spectra were obtained from layers A (the topmost layer), $\mathrm{B}_{1}$ (the bubbled or mottled contrast layer), $\mathrm{B}_{2}$ (the dark contrast layer), $\mathrm{B}_{3}$ (the light contrast layer) and $\mathrm{C}$ (substrate) as indicated in Fig. 1(a). The horizontal axis corresponds to the energy loss $(E)$, which is calibrated using the $\mathrm{Si}_{2,3}$ edge $(100 \mathrm{eV})$ and the $\mathrm{C} \mathrm{K}$ edge $(284 \mathrm{eV})$ in layer $\mathrm{C}$ (the SiC substrate). Back- 

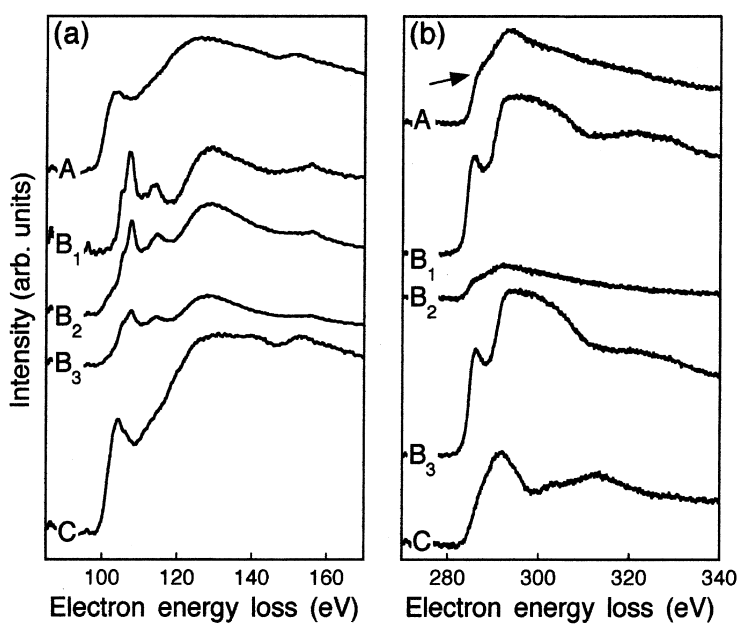

Fig. 3. (a) $\mathrm{Si} \mathrm{L}_{2,3}$ and (b) $\mathrm{C} \mathrm{K}$ edge EELS spectra obtained from $1.4 \times 10^{18} \mathrm{O}^{+} \mathrm{cm}^{-2}$ sample. A: topmost layer, $\mathrm{B}_{1}$ : bubbled or mottled contrast region, $\mathrm{B}_{2}$ : dark contrast region, $\mathrm{B}_{3}$ : light contrast region and $\mathrm{C}$ : substrate $\mathrm{SiC}$ in Fig. 1(b).

ground intensities $\left(I_{\mathrm{B}}\right)$ were removed from the spectra shown in Fig. 3 by subtraction using the power low model, $I_{\mathrm{B}}=A E^{-r}$ where $A$ and $r$ are fitting parameters [9]. The $\mathrm{Si} \mathrm{L}_{2,3}$ edge spectrum of the topmost layer (A) is almost same as that of the $\mathrm{SiC}$ substrate (C). On the other hand, the EELS spectra obtained from the damaged layer $\left(B_{1}, B_{2}\right.$ and $\left.\mathrm{B}_{3}\right)$ reveal a large contribution from $\mathrm{Si}^{4+}(107$ $\mathrm{eV}$ ), suggesting the formation of well-defined $\mathrm{SiO}_{2}$ layer at this fluence of $1.4 \times 10^{18} \mathrm{O}^{+} \mathrm{cm}^{-2}$ [10]. The center of the buried oxide layer $\left(\mathrm{B}_{2}\right)$ contains a highly diminished carbon concentration (Fig. 3(b)); excess carbon atoms are expelled on both sides of the buried oxide layer $\mathrm{B}_{2}$. This result is consistent with that obtained by STEM-EDX. The EELS spectra obtained from the $\mathrm{C} K$ edge (Fig. 3(b)) for damaged layers $B_{1}$ and $B_{3}$ reveal the appearance of the $\pi^{*}$ transition at $286 \mathrm{eV}$, in addition to the $\sigma^{*}$ transition at $293 \mathrm{eV}$. Barradas et al. [4] and Wesch et al. [5] have examined the oxygen ion implanted SiC using RBS and optical transmission and reflection measurements, respectively, and reported evidence of self-bonded carbon in the buried oxide layer and excess carbon atoms ejected to both sides of the buried oxide layer. Our present study clearly shows evidence for $\mathrm{sp}^{2}$ bonding in regions surrounding the buried oxide layer, and so is consistent with these results. It should be noted that the $\mathrm{C} \mathrm{K}$ edge spectrum from the topmost layer (A in Fig. 3(b)) possesses a shoulder as denoted by arrow. This may be attributed to the existence of slight chemical disordering induced by implantation.

\section{Conclusions}

Microstructural features, elemental distributions, and chemical bonding information in oxygen ion implanted $\mathrm{SiC}$ were examined by means of cross-sectional STEM-EDX/EELS. It was confirmed that a well-defined $\mathrm{SiO}_{2}$ layer including $\mathrm{sp}^{2}$ bonded carbon atoms is formed in the substrate implanted with $180 \mathrm{keV} \mathrm{O}^{+}$ions to fluences of $1.4 \times 10^{18} \mathrm{~cm}^{-2}$. Our present results suggest that oxygen implantation into $\mathrm{SiC}$ offers a way to produce a SiC-on-insulator structure, though many defects are observed to congregate near the interfaces between amorphous and crystalline structures. This study is the first to provide a oneto-one correspondence between microstructural features and chemical information such as elemental distributions and chemical bonding states.

\section{Acknowledgements}

We would like to thank J.R. Tesmer, M.G. Hollander, and C.R. Evans for their assistance with ion implantations. This work was supported by the Department of Energy, Office of Basic Sciences, Division of Materials Sciences. M.I. also acknowledges partial support from the Foundation of Kyushu Industrial Technology Center (KITEC) for his research abroad.

\section{References}

[1] K. Izumi, MRS Bull. 23 (1998) 20.

[2] Y.M. Liu, P.R. Prucnal, IEEE Photonics Technol. Lett. 5 (1993) 704

[3] S.M. Jackson, G.T. Reed, K.J. Reeson, Electron. Lett. 31 (1995) 1438.

[4] N.P. Barradas, C. Jeynes, S.M. Jackson, Nucl. Instr. and Meth. B 136/138 (1998) 1168. 
[5] W. Wesch, A. Heft, H. Hobert, G. Peiter, E. Wendler, T. Bachmann, Nucl. Instr. and Meth. B 141 (1998) 160.

[6] M. Ishimaru, R.M. Dickerson, K.E. Sickafus, Appl. Phys. Lett. 75 (1999) 352.

[7] M. Ishimaru, R.M. Dickerson, K.E. Sickafus, Proceedings of Microscopy and Microanalysis 99, 1999, p. 770.
[8] M. Ishimaru, K.E. Sickafus, Appl. Phys. Lett. 75 (1999) 1392.

[9] R.F. Egerton, Electron Energy-Loss Spectroscopy in the Electron Microscope, Plenum, New York, 1996.

[10] M. Ishimaru, T. Tsunemori, S. Harada, M. Arita, T. Motooka, Nucl. Instr. and Meth. 148 (1999) 311. 